\title{
Gene flow and reproductive success in ash (Fraxinus excelsior L.) in the face of ash dieback: restoration and conservation
}

\author{
Devrim Semizer-Cuming ${ }^{1,2,4} \mathbb{C} \cdot$ Igor Jerzy Chybicki $^{3} \cdot$ Reiner Finkeldey $^{1,5} \cdot$ Erik Dahl Kjær $^{2}$
}

Received: 1 July 2020 / Accepted: 16 December 2020 / Published online: 8 February 2021

(c) The Author(s) 2021

\begin{abstract}
- Key message Ash dieback decreases individual reproductive success of ash trees leaving healthy ash overrepresented as seed and pollen parents for next-generation seedlings. Substantial gene flow over hundreds of meters combined with superior fertility of healthy trees creates optimism for the species' future in European forests.

- Context Hymenoscyphus fraxineus is causing high mortality in European ash (Fraxinus excelsior L.). Due to inheritable resistance to the pathogen, natural selection is likely to act in favour of improved resistance in ash forests following natural regeneration. Still, the frequency of healthy trees is low, and the effect of natural selection will depend on survival, reproductive success and the dispersal capacity of healthy trees under natural conditions.

- Aims We aim to test whether healthy trees contribute more to the next generation and to infer their potential for dispersing progenies across the forested landscape.

- Methods Using parentage modelling, we estimate mating parameters and dispersal distances of seeds and pollen and compare realised reproductive success of healthy trees to that of unhealthy ones.

- Results Healthy trees are overrepresented as the parents of randomly sampled seeds and seedlings in the forest, although that is more pronounced on the female side. We observe long dispersal events and estimate the mean seed and pollen dispersal distances as $67 \mathrm{~m}$ and $347 \mathrm{~m}$, respectively.

- Conclusion Variation in reproductive success results in selection in favour of lowered susceptibility to ash dieback. The large dispersal capacity decreases the risk of genetic bottlenecks and inbreeding and allows resistant trees to disperse their genes into the neighbourhoods of substantial sizes.
\end{abstract}

Keywords Ash dieback $\cdot$ Enrichment planting $\cdot$ Fraxinus excelsior $\cdot$ Gene flow $\cdot$ Pollen and seed dispersal $\cdot$ Reproductive success

Handling Editor: Benoit Marçais

Contributions of the co-authors Conceptualisation: DS-C, EDK; methodology: DS-C, IJC, EDK; software: IJC; validation: DS-C, IJC, EDK; formal analysis: DS-C, IJC; investigation: DS-C, IJC, EDK; resources: RF, EDK; data curation: DS-C, IJC, EDK; writing—original draft: DS-C; writing—review \& editing: DS-C, IJC, RF, EDK; visualisation: DS-C, IJC, EDK; supervision: RF, EDK; project administration: DS-C, EDK; funding acquisition: DS-C, RF, EDK.

Devrim Semizer-Cuming

devrim.semizer-cuming@ forst.bwl.de

Igor Jerzy Chybicki

igorchy@ukw.edu.pl

Reiner Finkeldey

praesident@uni-kassel.de

Erik Dahl Kjær

edk@ign.ku.dk
1 Department of Forest Genetics and Forest Tree Breeding, Georg-August University of Göttingen, Büsgenweg 2, 37077 Göttingen, Germany

2 Department of Geosciences and Natural Resource Management, University of Copenhagen, Rolighedsvej 23, 1958 Frederiksberg C, Denmark

3 Department of Genetics, Institute of Experimental Biology, Kazimierz Wielki University, Chodkiewicza 30, 85-064 Bydgoszcz, Poland

4 Forest Research Institute of Baden-Wuerttemberg, Wonnhaldestraße 4, 79100 Freiburg im Breisgau, Germany

5 University of Kassel, Mönchebergstrasse 19, 34109 Kassel, Germany 


\section{Introduction}

Ash (Fraxinus excelsior L.) in Europe is severely affected by ash dieback, an emerging fungal disease, caused by the ascomycete Hymenoscyphus fraxineus (T. Kowalski) Baral, Queloz and Hosoya (Baral et al. 2014; Gross et al. 2014). Dieback of shoots, twigs and branches in the crown, wilting and premature shedding of leaves, necrotic lesions on leaves and in cambium, discoloration in bark and epicormic shooting are typical symptoms of the disease (McKinney et al. 2014; Skovsgaard et al. 2017). Dieback symptoms were observed in the northwest of Poland in 1992 (Kowalski 2006), but the disease has since spread over most of the native range of the species (McKinney et al. 2014; Pautasso et al. 2013). In Denmark, symptoms were first noticed in 2002 (Thomsen and Skovsgaard 2012), but the disease was already widespread by 2005, particularly in young stands (Skovsgaard et al. 2010).

Ash dieback is currently regarded as a serious threat to European biodiversity (Pautasso et al. 2013; Marçais et al. 2017; Enderle et al. 2019). There is overwhelming evidence of the severity of the problem across Europe (reviewed in Coker et al. 2019). Based on the surveys conducted in France and Belgium in 2010, Marçais et al. (2017) reported up to $35 \%$ annual mortality in young ash stands (diameter at breast height $(\mathrm{DBH})<5 \mathrm{~cm})$ 5-6 years after the pathogen arrival. In Lithuania, mortality rate in three different 8-year-old progeny trials reached $90 \%$ in 2010 , only 5 years after their establishment in 2005 (Pliūra et al. 2011). A dramatic decline from 2009 to 2012 was reported in ash tree populations in an 8-ha-old forest patch in Estonia, where $48 \%$ of overstorey and $39 \%$ of subcanopy trees died (Lõhmus and Runnel 2014). High mortality rates were also reported in the stands in north-western (21-39\%) and southeastern (30-95\%) Germany (Enderle et al. 2017; Lenz et al. 2016). In 2015, the fungus affected $50 \%$ of the ash trees $(\mathrm{DBH} \geq 10 \mathrm{~cm})$ in 22 forest observation plots in Switzerland (Queloz et al. 2017). Likewise, tree mortality rates in the Scandinavian monitoring sites have also been escalating (see Børja et al. 2017 for Norway; Bengtsson and Stenström 2017 for Sweden and McKinney et al. 2014 for Denmark).

Clonal and progeny trials of ash in Europe have revealed genetic variation in susceptibility to ash dieback with both narrow- and broad-sense heritability often reported above 0.4 (Enderle et al. 2015; Kjær et al. 2012; Lobo et al. 2014; 2015; McKinney et al. 2011; Muñoz et al. 2016; Pliūra et al. 2011; Stener 2013). This verifies that disease resistance is partially under genetic control. Assuming that the heritability of resistance is 0.5 and the frequency of resistant trees in pre-diseased ash forests is about $10 \%$, model simulations estimated that ash populations in the
UK woodlands would still exist in 100 years but decrease to about one-third of current levels (Evans 2019). It has thus been suggested that genetic variation in resistance may prove to be a long-term solution to ash dieback if natural selection is coupled with artificial selection (McKinney et al. 2014; Evans 2019). However, the frequency of ash trees with reasonable to high levels of genetic resistance (defined as crown damage below 10\%) within natural populations is low, $1-5 \%$ (Kjær et al. 2012; McKinney et al. 2014), and due to their long lifetime, no studies have yet measured the realised lifetime fitness of healthy trees with respect to their more susceptible neighbours in the surroundings (Kjær et al. 2012). The relative fitness of healthy trees can be negatively influenced if ash dieback damage triggers strong flowering among weakened trees. Our previous findings in a Danish clonal seed orchard of ash fortunately indicated a positive correlation between resistance to ash dieback and reproductive success (SemizerCuming et al. 2019). However, studies conducted in natural or semi-natural forests with mature trees of different size and age, spread over a heterogeneous area, have been lacking so far. The issue of fitness in natural ash populations is further complicated if the offspring of resistant trees are affected by increased inbreeding. This could be the case in the future if the majority of surviving trees in a genetically isolated area were the offspring of only a few old, resistant trees. Therefore, the recovery of ash forests will also rely on effective gene flow including seed dispersal at the forest and landscape scale (Semizer-Cuming et al. 2017). Gene flow is a complex process that incorporates biotic and abiotic interactions that affect mating, propagule production, dispersal, establishment, survival and maturation (Burczyk et al. 2004). Phenological synchrony and relative fecundity of individuals (Adams and Birkes 1991; Bochenek and Eriksen 2011; Chybicki and Burczyk 2013; Gleiser et al. 2018), propagule size and shape (Hintze et al. 2013), spatial distribution of individuals and populations (Klein et al. 2006; Robledo-Arnuncio et al. 2007), population size (Ellstrand and Elam 1993), topography of sites (Trakhenbrot et al. 2014) and atmospheric conditions (Jackson and Lyford 1999; Heydel et al. 2015) are among the factors influencing dispersal patterns of pollen and seeds. All these factors will shape the spatial genetic structure of the next generation of ash trees and thereby influence the long-term outcome of the ongoing natural selection in European ash forests.

Given the above background, the objectives of the present study are to estimate how ash dieback symptoms influence individual reproductive success and to assess seed and pollen dispersal in an ash forest suffering from ash dieback. Our hypothesis is that tolerant trees have higher reproductive success compared with damaged trees and therefore contribute 
disproportionally more to the next-generation recruitments. We applied a spatially explicit mating model to determine mating parameters and dispersal kernels of pollen and seeds. Sex expressions of the adult trees were modelled explicitly in order to reflect differences in a priori contribution of trees to seed and pollen pool. Flower intensity, fruit set, crown dieback intensity, height and basal area of the adult trees were incorporated into the model estimations to examine their effects on individual reproductive success, as well as to properly account for any differences in fecundity between trees when modelling the impact of crown damage on reproductive success.

\section{Materials and methods}

\subsection{Study site and sampling design}

The study site is located in Valby Hegn, Helsinge, Denmark (56 03'17" N 12。13'52" E) (Fig. 1). The sampling was conducted in the northern part of a 362.4 ha mixed continuous forest. Ash is an important species in the area, mainly as a mosaic of several smaller stands but also as single trees scattered within dominating beech and oak stands (Fig. 1). The ash stands in the forest are of different origin and age (Semizer-Cuming et al. 2020). The two stands in the west (1.0 ha) and in the north east (0.4 ha) include ash trees planted in 1958 based on seeds from an old-Danish seed orchard ('FP202' consisting of 8 clones) (Nielsen et al. 2009). Most other mature ash trees in the surveyed area are from 1934 to 1956 and of putative Danish origin, either from natural seeding or plantings with seeds procured from other Danish ash forests. There is a single record of a very small area $(<0.1 \mathrm{ha})$ planted with ash seedlings originated from Wiesbaden, Germany (unpublished records, The Nature Agency, Ostrupgaard, DK-3230 Græsted). The classical silvicultural practice for ash in the area has been planted with 2-4-year-old seedlings, but natural regeneration has also most likely been important and abundant natural regeneration is widely observed.

Bud and wood tissues were sampled from 469 reproductively mature ash trees in the stands (approximately $80 \%$ of the total number of mature ash trees in the study area). The ash trees are mainly located in the wetter areas and therefore not evenly distributed across the study area. The average density was calculated to about 20 mature ash trees per ha. The sampling of the mature trees in the 1.0-ha seed orchard offspring in the west (hereinafter $\mathrm{W}$ (FP202); Fig. 1) was exhaustive. Leaves from 399 naturally regenerated seedlings were sampled along two main transects stretching from the W (FP202) stand towards older trees in the forest (Fig. 1). Transect $1(\sim 210 \mathrm{~m})$ was placed in east-west direction whereas transect $2(\sim 180 \mathrm{~m})$ was placed in north-south direction (Fig. 1) as they represented the recruitment. The position of the seedlings along the two transects and their heights was recorded. Their age was estimated as 1-2 years but some could be older because ash seedlings can be repeatedly browsed by wildlife. Due to the small size of the seedlings (average height $=\sim 12 \mathrm{~cm}$ ) and the absence of observable symptoms, we assumed that ash dieback has not caused significant mortality among the sampled plants after they germinated. Finally, seeds were collected from 11 mother trees in order to obtain precise estimates of realised pollen dispersal using seeds from known mothers (Fig. 1).

\subsection{Characterisation of mature trees}

Geographical coordinates, heights and DBH of the mature trees were recorded, and basal areas were calculated based on DBH assuming circular stems (Semizer-Cuming et al 2020). Flowering was observed in May 2014: flower types were categorised as male, female or hermaphrodite, and flowering intensities were estimated based on a logarithmic scale, from 1 to 8 , according to Kjær and Wellendorf (1997). Crown damage (in all cases identified as ash dieback symptoms) was assessed individually for each tree in the summer 2014 as percent damage score (PDS) in seven classes: class $0=$ no damage, while classes from 1 to 5 represent increasing levels of damage $(<10 \%, 10-25 \%$, $25-50 \%, 50-75 \%$ and $75-100 \%$ ), and class 6 represents dead trees (100\% crown damage). Fruit set was also scored in the same summer as relative abundance, from 0 to 9 , where 0 means absence of fruits, while 1-3 indicates low, 4-6 is medium and 7-9 represents high abundance of fruits in crowns.

\subsection{DNA extraction and microsatellite analysis}

Total DNA was extracted from leaf, bud and embryo tissues using the DNeasy® 96 Plant Kit (Cat. no. 69181) and from wood tissues using the DNeasy® Plant Mini Kit (Cat. no. 69104 and 69106) according to the manufacturer's protocol (Qiagen, Hilden, Germany). The extraction protocol for the cambium included slight modifications: (1) AP1 + RNAse + polyvinylpyrrolidone (up to $10 \%$ end concentration) and (2) overnight incubation at $65{ }^{\circ} \mathrm{C}$. Seeds (50 per mother tree) were embedded in water for $1-2$ days for rehydration after their pericarp tissues were removed. Embryos were then carefully extracted to avoid endosperm or seed coat. Leaf, bud and embryo samples were ground 


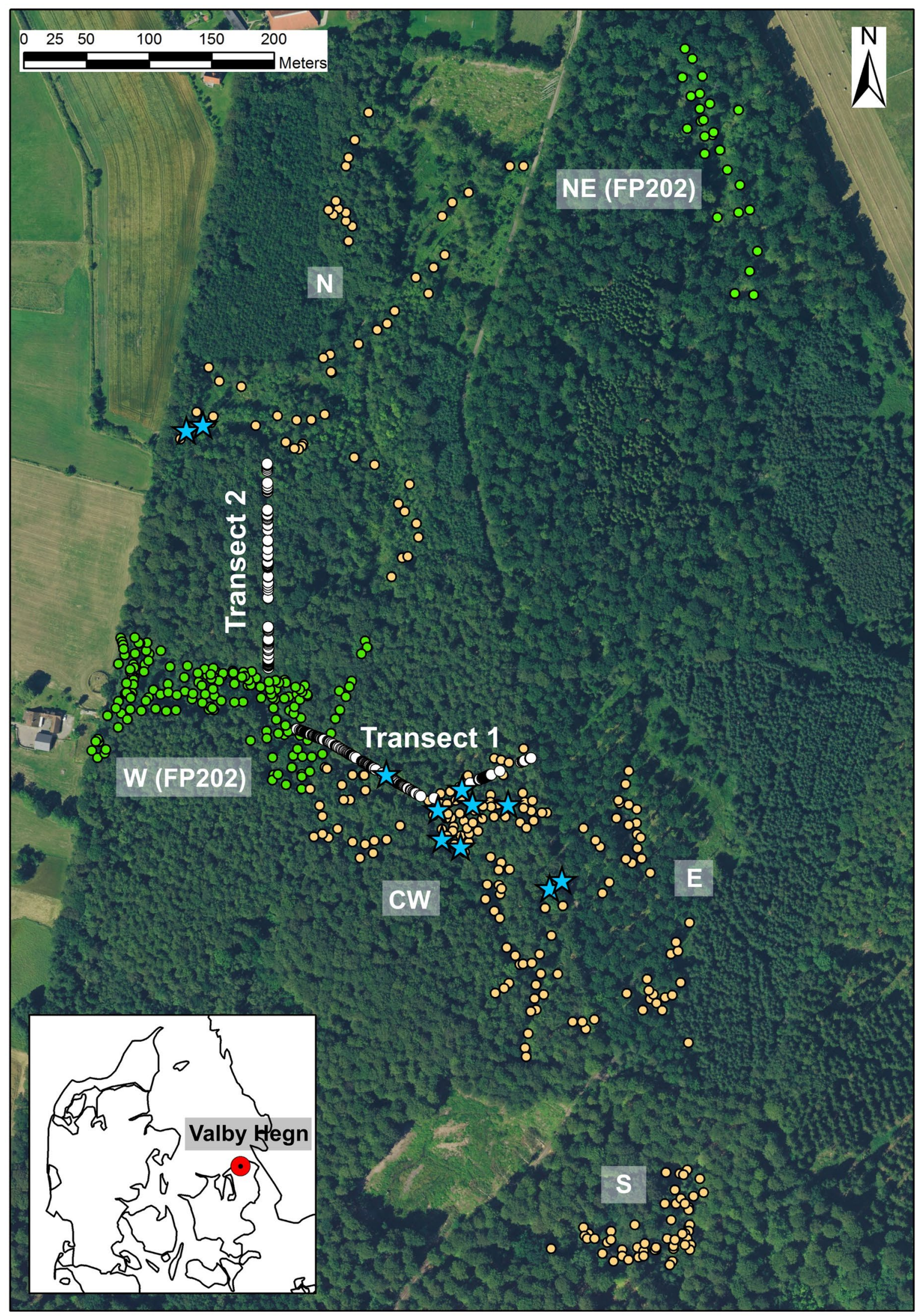

\section{פ springer INRAC}


४Fig. 1 Map of the study site and sampling design. Adult trees (green circles, FP202 seed orchard offspring planted in 1958; orange circles, ash trees established before 1958); progenies (blue stars, mother or seed trees; white circles, seedlings collected along two main transects); bottom left, location of the study site in Denmark. The maps were created using $\operatorname{ArcMap}^{\mathrm{TM}}$ 10.4.1, Copyright $@$ C ESRI

in 96-well plates with liquid nitrogen and $3 \mathrm{~mm}$ stainless steel beads in TissueLyser (Qiagen), whereas wood samples were prepared separately in Eppendorf tubes. Microsatellite analyses were carried out with 13 primers including FEMSATL8, FEMSATL11 and FEMSATL19 (Lefort et al. 1999), ASH2429 (Bai et al. 2011), FRESTSSR279, FRESTSSR308, FRESTSSR427 and FRESTSSR528 (Molecular Ecology Resources Primer Development Consortium et al. 2011) and Fp12378, Fp18437, Fp20456, Fp21064 and Fp104136 (Noakes et al. 2014) in four multiplexes. The reaction mixtures were subjected to PCR conditions combining a hot start with a touchdown procedure. The details of the microsatellite analysis concerning multiplexing, PCR conditions, allele size calling and binning can be found in Semizer-Cuming et al. (2017).

\subsection{Data analysis}

Number of alleles (A), effective number of alleles (Ae), observed heterozygosity (Ho) and expected heterozygosity $(\mathrm{He})$ were calculated using GenAlEx 6.502 (Peakall and Smouse 2006). Allelic richness $\left(A_{\mathrm{R}}\right)$ and private allelic richness $\left(\mathrm{PA}_{\mathrm{R}}\right)$ were computed using rarefaction method in HP-Rare (Kalinowski 2005), considering sampling size differences. INEST 2.2 (Chybicki and Burczyk 2009) was used for unbiased multilocus estimates of inbreeding coefficients within population $\left(F_{\text {IS }}\right)$. The software jointly estimated inbreeding coefficients, null allele rates and genotyping failures based on Bayesian approach at the parameter settings of 200,000 number of cycles, 2000 thinning and 20,000 burn-in.

We aimed to characterise the dispersal process as well as to test if there is any relationship between the crown damage due to ash dieback (scored as PDS; see the previous section) and the reproductive success of trees, treating female and male reproductive functions separately. For this purpose, we used the neighbourhood model (Adams and Birkes 1991; Burczyk et al. 2006), implemented in the $\mathrm{NM} \pi$ software version 1.2 (Chybicki 2018). The model has the advantage of taking simultaneously into account the effect of dispersal process (dispersal kernel) as well as the other confounding factors of reproductive success related to individual fecundity. Using a specifically designed regression analysis (Adams and Birkes 1991; Chybicki 2018), the method provides estimates of effect slopes (known as selection gradients; Morgan and Conner 2001) for putative covariates of reproductive success. In addition, the model treats unsampled parents (mostly due to either pollen or seed immigration) as well as self-fertilisation explicitly, so that effect slope estimates are also robust to the origin of progeny, which is treated as an unknown state (except for the cases when a parent is known explicitly, as in the case of seeds collected from mother trees).

The estimation of effect slopes for female and male reproductive success requires a sample of so-called "dispersed" progeny, i.e. the progeny with unknown both parents, such as naturally regenerated seedlings (Chybicki 2018). However, due to seed and pollen dispersal, seedlings typically provide much more information about female reproductive success than male reproductive success. Therefore, in order to balance the information content for each sex, to enable robust conclusions, we took the advantage of NM $\pi$ to treat "dispersed" and "non-dispersed" (seeds assigned to mother trees) progeny jointly in a single model. It should be stressed that seedlings represented mostly up to 2-year-old individuals, so that their survival was believed to be not affected by the pathogen, and that the estimated effect slopes reflected only differences in female and male reproductive success at the adult stage.

The following characters were included into the model as potential covariates of reproductive success: (i) flowering intensity (for male reproductive success only), (ii) fruit set (for female reproductive success only), (iii) height (both female and male function), (iv) basal area (both female and male function) and (v) PDS (both female and male function). All phenotypic characters were treated as quantitative variables and standardised prior to the estimation. Including flowering intensity, fruit set, height and basal area in addition to the main covariate of interest (PDS) was motivated by our a priori expectation that these characters are directly linked to individual fecundity and can exhibit individual variation due to factors not related to PDS. Such variation can reflect intrinsic (genetic) differences between individuals as well as differences in micro-site quality (e.g. nutrients, light, exposition to wind, etc.). Consequently, obtained effect slopes for PDS should be treated as rather conservative estimates because a fraction of the total PDS effect is likely captured by the effects of the fecundity-related covariates, especially the effect of flowering intensity and fruit set.

In the model, the gender expressions of the putative parents was incorporated as suggested in the program manual ( 1 denoted female, 0 described male and 0.5 indicated hermaphrodite or unknown gender, according to field observations) (see the Eq. 2a and 2b in Chybicki 2018 for more details). Incorporation of sex data allowed us to avoid potential bias in dispersal kernels and effect slopes that could result from uniform expectations of the female 
and male reproductive output for true hermaphrodites and male- or female-skewed individuals. To model the seed and pollen dispersal process, we adopted the exponentialpower kernel, offering enough flexibility to fit different shapes and scales of the actual probability distribution of dispersal distances (Nathan et al. 2012; Bullock et al. 2017). It should be stressed that including the distance effect into the model was necessary and also a means to account for the distance effect, which otherwise could affect the estimates of effect slopes for the covariates of reproductive success. In this way, we were able to disentangle the effect of spatial proximity of a parent and the effect of phenotypic characters. It is worth noting that the estimated dispersal kernels remain independent of the size and shape of the sample plot, providing a robust description of the dispersal process, especially when compared with empirical distributions of dispersal distances obtained through parentage reconstruction (which are strongly plotdependent) (Nathan et al. 2012). Also, unlike empirical distribution, estimated dispersal kernels provide estimates of the true (i.e. not plot-constrained) mean dispersal distance as well as the other quantiles of dispersal kernel. Because some candidate parents in the study plot were not included in the sample, the so-called seed and pollen immigration rates should be considered as a sum of the true immigration rate and the frequency of maternity or paternity of unsampled candidates. Therefore, we focused on dispersal kernels as the main source of information about gene flow.

A backward elimination approach (Arnold 2010) was applied to select the best-fitting model, with statistically significant effect slopes for phenotypic variables (Table 7 in Appendix). The backward approach started with the full model including all phenotypic variables and successively refitted the reduced models after excluding the least significant variable, i.e. the variable for which the selection gradient was characterised by the highest $p$ value using the likelihood ratio test (Chybicki 2018). The procedure ended when any further elimination produced a significantly worse model $(\alpha=0.05)$. In addition, the Akaike information criterion (AIC; Burnham and Anderson 2002) was used to compare model fit after penalizing model dimensionality.

In addition to the modelling approach, we also performed some direct comparisons as follows. Based on the best fitting model, for each progeny, the two most likely genealogies were reconstructed, and their posterior probabilities were estimated (Chybicki 2018). The inferred genealogy was considered as true when the probability was $\geq 0.8$. Seedling genealogies were used to determine the realised contribution of the parents to the gamete pool, specifically pollen and seed dispersal from the W (FP202) stand to the seedlings distributed along the transect lines in the neighbouring forest (cf. Fig. 1).
Table 1 Adult population gender demographics and mean crown damage levels

\begin{tabular}{|c|c|c|c|}
\hline Stand ID & $N$ & Gender $(\mathrm{m} / \mathrm{h} / \mathrm{f})$ & Mean PDS \\
\hline \multirow[t]{4}{*}{ NE (FP202) } & 11 & $\mathrm{~m}$ & 30.0 \\
\hline & 7 & $\mathrm{~h}$ & 33.6 \\
\hline & 8 & $f$ & 36.2 \\
\hline & 26 & & 33.3 \\
\hline \multirow[t]{4}{*}{ W (FP202) } & 55 & $\mathrm{~m}$ & 33.7 \\
\hline & 66 & $\mathrm{~h}$ & 65.6 \\
\hline & 52 & $\mathrm{f}$ & 35.9 \\
\hline & 173 & & 45.1 \\
\hline \multirow[t]{4}{*}{$\mathrm{N}$} & 24 & $\mathrm{~m}$ & 33.1 \\
\hline & 26 & $\mathrm{~h}$ & 63.6 \\
\hline & 9 & f & 42.2 \\
\hline & 59 & & 46.3 \\
\hline \multirow[t]{4}{*}{$\mathrm{CW}$} & 47 & $\mathrm{~m}$ & 30.9 \\
\hline & 55 & $\mathrm{~h}$ & 54.0 \\
\hline & 18 & $\mathrm{f}$ & 41.2 \\
\hline & 120 & & 42.0 \\
\hline \multirow[t]{4}{*}{ E } & 11 & $\mathrm{~m}$ & 38.6 \\
\hline & 16 & $\mathrm{~h}$ & 93.0 \\
\hline & 10 & $\mathrm{f}$ & 54.0 \\
\hline & 37 & & 61.9 \\
\hline \multirow[t]{4}{*}{ S } & 15 & $\mathrm{~m}$ & 52.5 \\
\hline & 33 & $\mathrm{~h}$ & 73.8 \\
\hline & 6 & $\mathrm{f}$ & 58.3 \\
\hline & 54 & & 61.7 \\
\hline
\end{tabular}

$N E$ north east, $W$ west, $N$ north, $C W$ central west, $E$ east, $S$ south, $N$ number of individuals, Gender $(\mathrm{m} / \mathrm{h} / \mathrm{f})$ male, hermaphrodite and female genders, Mean PDS mean percent damage score

The adult trees in the stands ' $\mathrm{NE}$ and $\mathrm{W}$ ' are originated from the FP202 seed orchard

The average health (PDS) of the parents of the progenies (seeds and seedlings) was calculated and compared with that of all mature trees in order to determine if the identified parent trees represent the healthier group within the mature trees. We applied a randomisation approach (999 permutations) to test whether it is likely that the observed parents (either mothers or fathers) were simply drawn from the population of all candidate parents of the given gender, regardless of their PDS values.

\section{Results}

Adult population gender demographics and mean crown damage levels (PDS) are summarised in Table 1. Except for the stand in the north east, crown damage was higher in hermaphrodites than in females and males in all stands, and 
Table 2 Genetic diversity parameters for the adult trees and progenies

\begin{tabular}{lllllllll}
\hline & $N$ & $A$ & $A_{\mathrm{R}}$ & $\mathrm{PA}_{\mathrm{R}}$ & $\mathrm{Ae}$ & $\mathrm{Ho}$ & $\mathrm{He}$ & $F_{\mathrm{IS}}$ \\
\hline Adults & & & & & & & & \\
$\quad \mathrm{NE}$ (FP202) & 26 & 5.923 & 5.880 & 0.210 & 3.486 & 0.418 & 0.515 & 0.174 \\
$\mathrm{~W}$ (FP202) & 173 & 8.385 & 5.690 & 0.210 & 3.510 & 0.473 & 0.510 & 0.047 \\
$\mathrm{~N}$ & 59 & 7.154 & 5.990 & 0.330 & 3.768 & 0.516 & 0.530 & 0.033 \\
$\mathrm{CW}$ & 120 & 7.615 & 5.640 & 0.170 & 3.630 & 0.530 & 0.541 & 0.042 \\
$\mathrm{E}$ & 37 & 5.846 & 5.480 & 0.190 & 3.479 & 0.425 & 0.505 & 0.136 \\
$\mathrm{~S}$ & 54 & 6.231 & 5.290 & 0.220 & 3.193 & 0.449 & 0.536 & 0.160 \\
Progenies & & & & & & & & \\
$\quad$ SDL & 399 & 8.538 & 5.660 & 0.180 & 3.616 & 0.494 & 0.524 & 0.017 \\
SD & 550 & 8.538 & 5.360 & 0.120 & 3.802 & 0.524 & 0.535 & 0.002 \\
\hline
\end{tabular}

$N E$ north east, $W$ west, $N$ north, $C W$ central west, $E$ east, $S$ south, $S D L$ seedlings, $S D$ seeds, $N$ number of individuals, $A$ mean number of alleles, $A_{R}$ allelic richness corrected for sample size, $P A_{R}$ private allelic richness corrected for sample size, Ae effective number of alleles, $\mathrm{Ho}$ observed heterozygosity, $\mathrm{He}$ expected heterozygosity, $F_{I S}$ mean inbreeding coefficient (Avg Fi)

The adult trees in the stands 'NE and W' are originated from the FP202 seed orchard overall mean crown damage levels ranged between 33.3 and $61.9 \%$ (Table 1).

Genetic diversity parameters for the adult trees and progenies are given in Table 2. Of 469 adult trees, only 10 could not be genotyped at a single locus whereas no genotyping failure existed either of the progeny data set. Population genetic parameters related to allelic richness or heterozygosity showed no signs of reduction in the progenies compared with the parental generation, and the estimated inbreeding coefficients were low in the progenies compared with the parents (Table 2).

The full model incorporating all selection gradients performed better $(\mathrm{AIC}=37,406.1, p<0.001)$ when compared with the null model without any selection gradients (AIC $=37,798.9)$ (Table 3). The backward elimination of the selection gradients starting from the full model (Table 7 in Appendix) indicated that the model without tree height and female basal area performed best (AIC $=37,402.5$; Table 3).

The mating model parameters and the standard errors computed based on the best model are given in Table 4 . The estimated dispersal kernel parameters and the approximate
95\% confidence interval around them are given in Table 5. According to the model estimations, the frequency of seed and pollen immigration from the surrounding sources were $24.3 \%$ and $40.4 \%$, respectively, and there was no selffertilisation (Table 4). Both seed and pollen dispersal kernels followed a fat-tailed distribution $\left(b_{\mathrm{s}}=0.672, b_{\mathrm{p}}=0.229\right.$; Tables 4 and 5). The mean dispersal distances of seed $\left(\delta_{\mathrm{s}}\right)$ and pollen $\left(\delta_{\mathrm{p}}\right)$ were estimated at $67.2 \mathrm{~m}$ and $346.7 \mathrm{~m}$, respectively (Tables 4 and 5).

The cumulative probability distributions of seed and pollen dispersals based on the best model (Fig. 2) predict that $50 \%$ of the seeds disperse within $50 \mathrm{~m}$, whereas less than 5\% seeds travel further than $180 \mathrm{~m}$, while the likelihood for dispersal beyond $300 \mathrm{~m}$ is less than $1 \%$. For pollen, the model predicts that $50 \%$ of the pollen successfully disperses up to $140 \mathrm{~m}, 5 \%$ beyond $1.3 \mathrm{~km}$ and $1 \%$ even further than $3 \mathrm{~km}$ from the source tree.

Based on the best model predicted for the study population, the observed fruit set is positively related to realised female reproductive success (0.482), and similarly, flower intensity is also positively related to realised male

Table 3 Model comparison parameters for the null, full and the best model

\begin{tabular}{lllllllllllll}
\hline Model & LogL & npar & AIC & $p$-val (LR) & FS_g & PDS_g & H_g & BA_g & FI_b & PDS_b & H_b & BA_b \\
\hline Null & $-18,880.5$ & 19 & $37,798.9$ & - & 0 & 0 & 0 & 0 & 0 & 0 & 0 & 0 \\
Full & $-18,676.1$ & 27 & $37,406.1$ & $2.43 \mathrm{E}-83^{*}$ & 1 & 1 & 1 & 1 & 1 & 1 & 1 \\
Best & $-18,677.2$ & 24 & $37,402.5$ & $0.497^{* *}$ & 1 & 1 & 0 & 0 & 1 & 1 & 0 & 1 \\
\hline
\end{tabular}

$\log L \log$-likelihood, npar number of parameters, AIC Akaike information criterion, $p$-val ( $L R) p$ value of the likelihood ratio test; selection gradient series: $F I$ flower intensity, $F S$ fruit set, $P D S$ percent damage score, $H$ height, $B A$ basal area, $g$ (gamma) female selection gradient, $b(b e t a)$ male selection gradient, $1 / 0$ included/excluded selection gradient

${ }^{*} p$ value of the LR test for the difference in fit between the null and full model

** $p$ value of the LR test for the difference in fit between the full and the best model according to the backward elimination procedure 
Table 4 Mating model parameters based on the best model

\begin{tabular}{llllllll}
\hline Parameter & $\mathrm{s}$ & $\mathrm{ms}$ & $\mathrm{mp}$ & $1 / \delta_{\mathrm{s}}$ & $1 / \delta_{\mathrm{p}}$ & $b_{\mathrm{s}}$ & $b_{\mathrm{p}}$ \\
\hline Estimate & 0 & 0.243 & 0.404 & 0.015 & 0.003 & 0.672 & 0.229 \\
Std. Error & - & 0.0259 & 0.0196 & 0.0020 & 0.0016 & 0.1086 & 0.0522 \\
\hline
\end{tabular}

$s$ probability of self-fertilisation, $m s$ probability of seed immigration, $m p$ probability of pollen immigration, $\delta_{s}$ mean distance of seed dispersal $(\mathrm{m}), \delta_{p}$ mean distance of pollen dispersal $(\mathrm{m}), b_{s}$ shape of seed dispersal kernel, $b_{p}$ shape of pollen dispersal kernel reproductive success (1.246) (Table 6). The relationship between crown damage (PDS) and reproductive success is negative for both female $(-0.674)$ and male $(-0.238)$, i.e. the healthiest trees (low PDS) have the highest likelihood of contributing gametes to the next generation. Tree size (BA) is negatively related to male reproductive success $(-0.361)$. All of the estimates were statistically significant $(p<0.05)$.

Based on the best-fitting model, 180 (45\%) most likely maternal and 285 (52\%) most likely paternal genealogies were, respectively, inferred for the seedlings and seeds, which possessed at least the minimum threshold probability of 0.8. The signs of gene flow from the W (FP202) stand could be observed in the surrounding forest. The maternal profile of the seedlings along the two transects (Fig. 1) showed that $39 \%$ of the seedlings that were successfully assigned parentage originated from the seeds dispersed from the trees in the W (FP202) stand, while $61 \%$ of them came from the other trees in the area. The paternal contribution from the W (FP202) stand to the seedlings with assigned parentage was quite similar (31\%), whereas the other trees in the area sired $69 \%$ of the seedlings. These are the average figures for the two transects, but there was a clear pattern where the contribution from the trees in the W (FP202) stand decreased rapidly with the distance from the stand, as would be expected (Fig. 3). A total of $7 \%$ of the seeds collected from the trees 100-200 m east from the border of the W (FP202) stand (see Fig. 1) were sired by the trees in the W (FP202) stand.

Table 5 Dispersal kernel parameters estimated at 95\% confidence interval $(Q)$

\begin{tabular}{llll}
\hline Parameter & Estimate & $Q(2.5 \%)$ & $Q(97.5 \%)$ \\
\hline$\delta_{\mathrm{s}}$ & 66.6 & 54.1 & 86.7 \\
$b_{\mathrm{s}}$ & 0.672 & 0.407 & 0.938 \\
$\delta_{\mathrm{p}}$ & 346.7 & 154.1 & $\mathrm{ND}$ \\
$b_{\mathrm{p}}$ & 0.229 & 0.101 & 0.357 \\
\hline
\end{tabular}

$\delta_{s}$ mean of the seed dispersal kernel $(\mathrm{m}), b_{s}$ shape parameter of the seed dispersal kernel, $\delta_{p}$ mean of the pollen dispersal kernel (m), $b_{p}$ shape parameter of the pollen dispersal kernel, $N D$ not determined
The mean crown damage level (i.e. mean PDS) of the assigned fathers of the seedlings was only $26 \%$ compared with a general damage level of $51 \%$ among the assessed males in the population (Fig. 4a, b). The difference was similarly large for the female trees, where the assigned mothers of the seedlings showed an average damage level of $25 \%$, again much lower than the general damage level of $57 \%$ among females in the population (Fig. 4c, d). Based on the randomisation test, the differences between the groups were highly significant $(p<0.001)$.

\subsection{Discussion}

The most important finding in our study is that crown damage due to ash dieback reduces individual reproductive success. Although this is in line with our previous findings in a Danish seed orchard of ash (Semizer-Cuming et al. 2019), here we showed for the first time that naturally recruited ash seedlings tend to have seed and pollen parents among healthy trees. Additionally, as in the seed orchard study, the intensity of the effect appeared to be stronger in females $(-0.674)$ than males $(-0.238)$. The replicated observation of difference between sexes strongly suggests that ash dieback influences male and female reproductive functions differently. This may result from intrinsic differences between maternal and paternal investments because the cost of reproduction is usually higher for

Table 6 Selection gradients for the phenotypic variables of individual reproductive success within the study population

\begin{tabular}{llllll}
\hline & FS & FI & PDS & BA \\
\cline { 4 - 5 } & Female & Male & Female & Male & Male \\
\hline Estimate & $0.482^{*}$ & $1.246^{*}$ & $-0.674^{*}$ & $-0.238^{*}$ & $-0.361^{*}$ \\
Std. error & 0.064 & 0.142 & 0.114 & 0.088 & 0.104 \\
\hline
\end{tabular}

$F S$ fruit set, $F I$ flower intensity, $P D S$ percent damage score, $B A$ basal area

${ }^{*} p<0.05,{ }^{* *} p<0.01,{ }^{* * *} p<0.005$ 

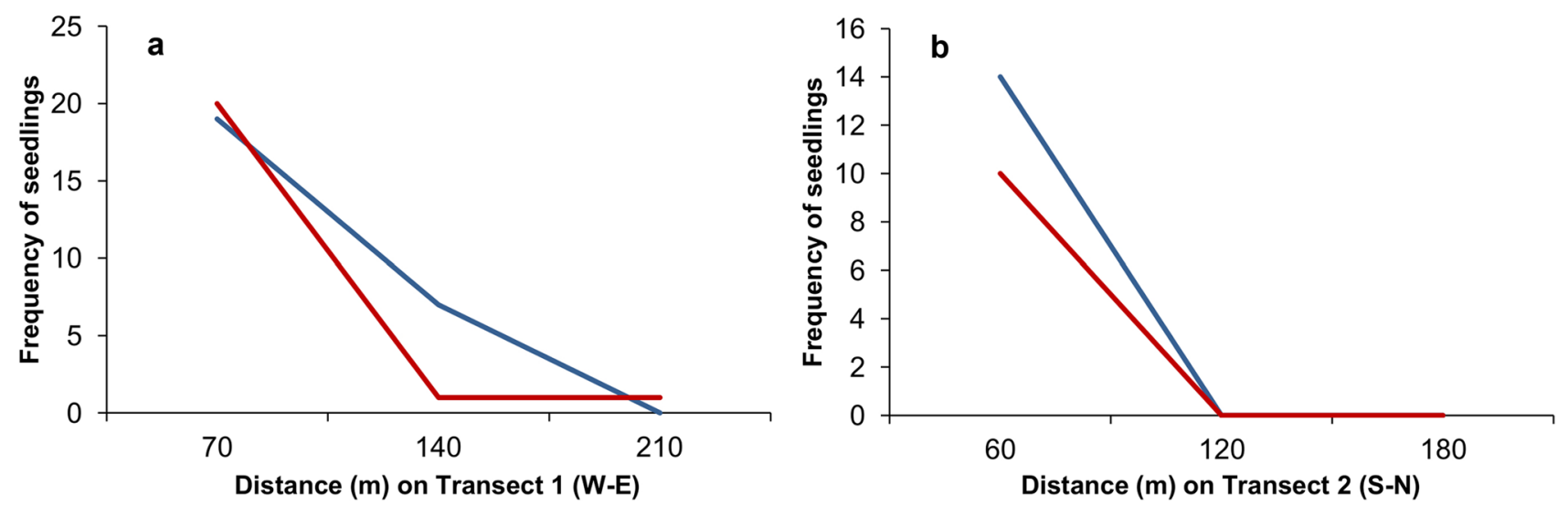

Fig. 2 Gamete dispersal curves along transects 1 (a) and 2 (b) from the W (FP202) stand into the surrounding ash populations. Blue lines, both parents are from the planted stand; red lines, one parent is from the planted stand

females than for males (Obeso 2002). If resources are limited due to crown damage and reproduction is much costlier for females, unhealthy females cannot produce enough mature seeds while some of their male counterparts can still produce enough viable pollen to reproduce. Stress conditions can occasionally enhance flowering as an emergency response in order to produce the next generation (Wada and Takeno 2010), and biotic stress caused by $H$. fraxineus could lead ash individuals to compromise between reproduction and defence response (Denancé et al. 2013). Since dieback tolerance is partly inherited, increased flowering of unhealthy trees could, in theory, slow down the process of natural selection. However, our study points towards a substantial positive correlation between health and reproductive success. It is worth noting that the regression model allows variation in flowering intensity and fruit set to explain variation in reproductive success. Both variables are likely to capture a fraction of the total effect of pathogen, and the net effect of pathogen on reproductive success can therefore be even stronger. With this kept in mind, our results show that variation in reproductive success can increase the speed of natural selection in favour of tolerant ash trees, because they have not only lower risk of mortality but also higher chance of producing offspring (most pronounced on the female side).

The assessment of selection based on the paternity analysis of seeds only reflects variation in male reproductive fitness, while estimates of variation in reproductive success based on seedlings may include a minor effect of early selection created by mortality due to ash dieback. However, we expect that the parentage analysis of the seedlings mainly reflects reproductive variation among mature trees because the young seedlings had no observable disease symptoms when they were sampled.

Our study also revealed considerable seed and pollen dispersal in the relatively dense stand. Pure ash forests in Denmark between 50 and 100 years typically contain 100-200 mature trees per ha with an average distance between the nearest trees of approximately 7-10 m. However, the distance between very healthy mates would easily become $50-100 \mathrm{~m}$ with only $2 \%$ of highly resistant trees. Estimated dispersal kernels, as well as the results of previous studies (Bacles et al. 2005;

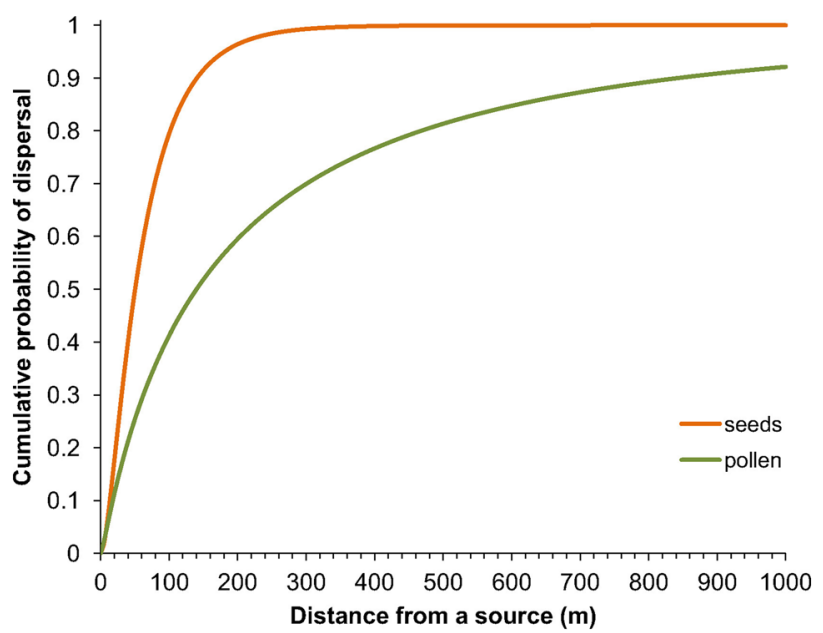

Fig. 3 Cumulative probability distributions of seed and pollen dispersal 
Bacles and Ennos 2008; Semizer-Cuming et al. 2017), suggest that such trees would still be able to mate and be highly successful in transmitting their genes to the next generation compared with unhealthy trees. Our estimated seed dispersal distances (average $67 \mathrm{~m}$ ) show that 2 to 4 healthy trees per ha will probably be able to disperse seeds onto the forest floor among them. This fits well with our population genetic analyses that revealed no indication of reduced diversity or increased inbreeding in the seedlings compared with the mature trees in the studied forest. However, in mixed stands with a lower frequency of ash trees, distances between putatively resistant trees can be larger than the estimated pollen dispersal distances, and especially, dispersal into suitable microhabitats via seeds may become a limiting factor, at least within a single generation. More studies are required to analyse these dispersal dynamics in such forests.

On a larger spatial scale, pollen and seed dispersal distances are important to prevent the risk of population fragmentation in future landscapes in the absence of long-distance dispersal (LDD). Long-distance seed dispersal is vital for species' colonisation at suitable sites in managed and unmanaged forests and open landscapes (Cain et al. 2000; Kramer et al. 2008). We did not specifically examine LDD in the present study, but the cumulative probability distributions of dispersal distances suggest that such events are likely in the species (Fig. 3). A study of a severely fragmented $F$. excelsior population in Scotland estimated the mean pollen dispersal distance of $328 \mathrm{~m}$ (Bacles et al. 2005) and up to $1.9 \mathrm{~km}$ (Bacles and Ennos 2008) with $8 \%$ of the effective seed dispersal originating from dispersals between $100 \mathrm{~m}$ and $3 \mathrm{~km}$ (Bacles et al. 2006). In the fragmented landscape of Rösenbeck in Germany, we have previously estimated that the mean dispersal distance of $F$. excelsior pollen was even greater $(571 \mathrm{~m})$, with a proportion of pollen most likely representing LDD events (Semizer-Cuming et al. 2017). A shorter average dispersal distance of pollen $(197 \mathrm{~m})$ was estimated in Japanese $F$. mandshurica located in a forest reserve in Hokkaido (Goto et al. 2006). Altogether, the results show that though the majority of the dispersal events in ash occurs in short distances, rare LDD over hundreds and thousands of meters, in particular of pollen, may still keep fragmented ash populations connected with each other in future landscapes.

We observed that healthy trees were overrepresented as parents for the next generation. The assigned parents on average showed half the level of crown damage compared with that of the general damage level in the study population. The implication is that the next
Fig. 4 Mean crown damage levels (PDS) of the male and female trees in the study population: PDS of a all potential fathers versus $\mathbf{b}$ assigned fathers of the seedlings and $\mathbf{c}$ all potential mothers versus $\mathbf{d}$ assigned mothers of the seedlings
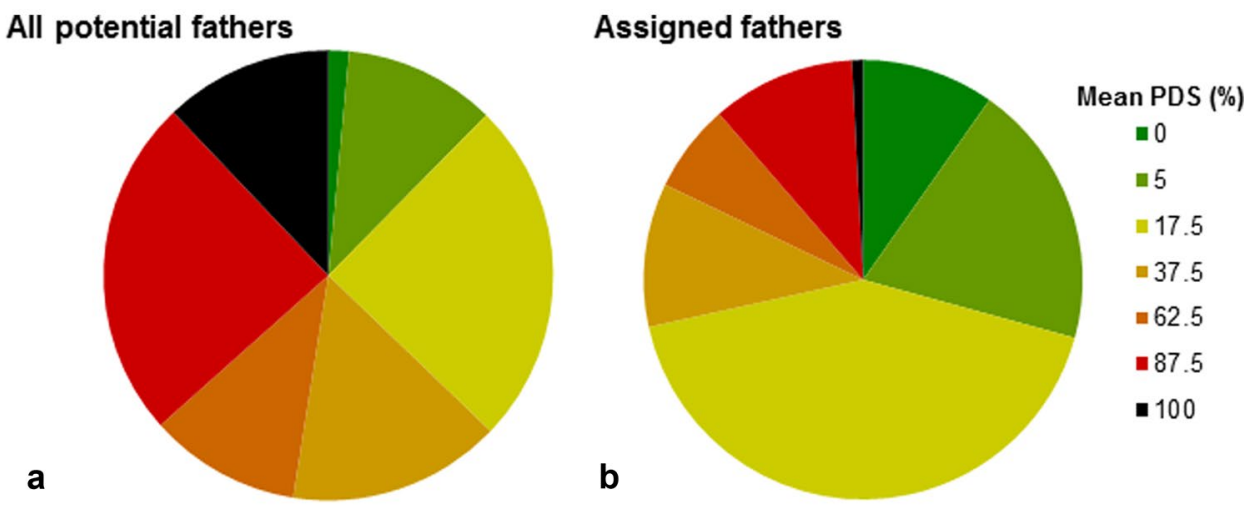

All potential mothers

C

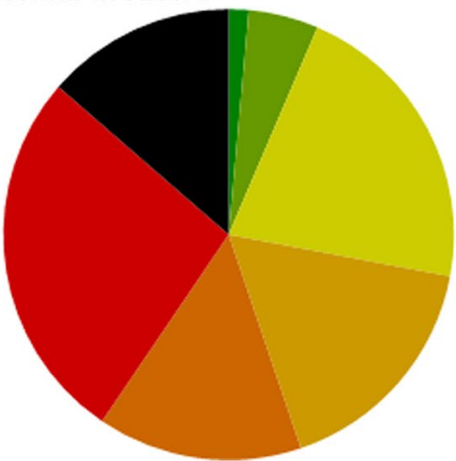

\section{Assigned mothers}

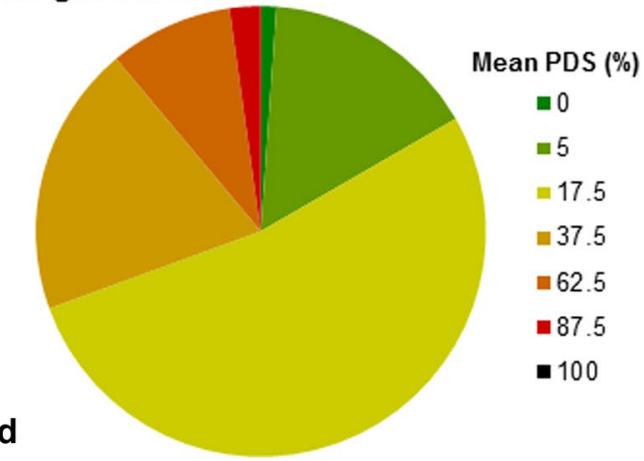


generation will have reduced susceptibility to ash dieback because the trait is known to be partly heritable, as discussed in the introduction. However, estimates of narrow sense heritability have so far been based on the studies of half-sib families grown in plantations. Lobo et al. (2015) applied parent-offspring regression to verify that resistance to ash dieback is inherited but still based on planted offspring grown under field trial conditions. Wohlmuth et al. (2018) studied parentoffspring correlation in damage level under in situ conditions in Austria but did not find significant narrow-sense heritability. However, data from Danish breeding activities revealed that crown damage levels of old mature trees were significantly correlated with their susceptibility levels to ash dieback when tested in a clonal trial (Kjær, personal communication). This supports that healthy mature trees in our study site most likely represent the trees with improved level of genetic resistance. The fact that offspring tend to have parents among healthy trees is very positive because the current frequency of trees with very high level of resistance is generally low in native ash forests. And we do expect that selection in favour of offspring from healthy parents will continue as the seedlings grow older (zygotic selection) because several trials have revealed higher mortality in susceptible families (Kjær et al. 2012; Lobo et al. 2014; Muñoz et al. 2016).

Finally, our findings suggest that plantations with resistant ash trees can modify the gene pool of existing forests not only by replacing them but also by exchanging genes. Gene flow from commercial ash plantings into oldgrowth forests may have negative implications for gene conservation, including the risk of lost genetic diversity and patterns of local adaptation (Semizer-Cuming et al. 2017). However, in the face of ash dieback, gene flow from new plantations into the existing native forests can become an important process, based on the idea of enrichment planting. Genetic enrichment with improved resistance can be a way to enrich the otherwise rapidly decreasing fitness of native ash populations and thereby restore their ability to compete with other species, while partly preserving existing genetic patterns of local adaptation. Our Fig. 4 shows that the trees with crown damage levels between 10 and $25 \%$ (i.e. mean PDS of $17.5 \%$ ) still maintain a relatively high reproductive success. From an evolutionary perspective, this suggests that the reproductive success of a tree (in its overall life-span) is kept even at $25 \%$ of crown damage. Contribution from such trees to next generation will probably reduce the risks of genetic bottlenecks and loss of gene diversity that might be crucial for future adaptive processes, because completely healthy trees are often rare in damaged ash forests. However, their contribution can also reduce the efficiency of selection in favour of completely healthy ash trees and thereby slow down the build-up of resistance to ash dieback.

We expect that an enrichment plantation, once mature, is likely to create a zone of few hundred meters next to its borders, where a reasonable frequency of next-generation seedlings with one or two parents from the enrichment trees, while a larger zone will contain seedlings with one of the parents originating from the enrichment trees. Thomasset et al. (2014) raised the conservation concern that the dispersal of genes from planted into native populations may decrease local adaption. It is important that future planted European ash forests remain adapted to local growth conditions. This speaks in favour of developing ash enrichment seed sources based on the multiple population concept (cf. Eriksson et al. 1993) in order to encompass large variation in ecological conditions within the natural distribution of common ash in Europe. This fits well with tree improvement and selection programs initiated simultaneously in many European countries, thereby covering many different eco-regions.

\section{Conclusion}

Our results predict that the next generation of ash trees from natural seed fall will have improved levels of tolerance to ash dieback compared with their parental generation due to the interplay between sexual and zygotic selection. This is promising for the future health of the species in European forests, although we still cannot judge if gained natural resistance will be sufficient to allow the ash trees to maintain their ecological niche in the long run. Our results further suggest that natural recovery can be enriched by plantings with seeds from ash genotypes selected and tested in seed orchards for high level of disease tolerance, because healthy trees in such plantings are expected to spread their seeds and pollen several hundred meters into the surrounding ash stands in managed forests. Human intervention may thus prove a valuable tool to ensure the future existence of ash in European forests and ecosystems when based on sound genetic principles, but our results also provide hope for the natural recovery of protected forests without intervention. It is important to follow the dynamics in the present and other survey areas in the years to come to reveal if and how zygotic selection until maturity can continuously increase the representation of offspring from healthy parents and to provide in situ heritability estimates relevant to natural selection under forest conditions. 


\section{Appendix}

Table 7 Backward elimination of the selection gradients

\begin{tabular}{|c|c|c|c|c|c|c|c|c|c|c|c|c|c|}
\hline Step & Model & $\log L$ & $\mathrm{df}$ & AIC & FS_g & PDS_g & H_g & BA_g & FI_b & PDS_b & H_b & BA_b & $p$ value \\
\hline 0 & M0 & $-18,676.1$ & 27 & $37,406.10$ & 1 & 1 & 1 & 1 & 1 & 1 & 1 & 1 & NA \\
\hline 1 & M1 & $-18,704.0$ & 26 & $37,460.04$ & 0 & 1 & 1 & 1 & 1 & 1 & 1 & 1 & 7.47E-14 \\
\hline 1 & M2 & $-18,694.6$ & 26 & $37,441.14$ & 1 & 0 & 1 & 1 & 1 & 1 & 1 & 1 & $1.16 \mathrm{E}-09$ \\
\hline 1 & M3 & $-18,676.1$ & 26 & $37,404.16$ & 1 & 1 & 0 & 1 & 1 & 1 & 1 & 1 & 0.806496 \\
\hline 1 & M4 & $-18,676.1$ & 26 & $37,404.12$ & 1 & 1 & 1 & 0 & 1 & 1 & 1 & 1 & 0.887537 \\
\hline 1 & M5 & $-18,727.4$ & 26 & $37,506.84$ & 1 & 1 & 1 & 1 & 0 & 1 & 1 & 1 & $3.82 \mathrm{E}-24$ \\
\hline 1 & M6 & $-18,678.9$ & 26 & $37,409.70$ & 1 & 1 & 1 & 1 & 1 & 0 & 1 & 1 & 0.017960 \\
\hline 1 & M7 & $-18,677.1$ & 26 & $37,406.20$ & 1 & 1 & 1 & 1 & 1 & 1 & 0 & 1 & 0.147299 \\
\hline 1 & M8 & $-18,683.6$ & 26 & $37,419.10$ & 1 & 1 & 1 & 1 & 1 & 1 & 1 & 0 & 0.000108 \\
\hline 2 & M9 & $-18,705.5$ & 25 & $37,461.08$ & 0 & 1 & 1 & 0 & 1 & 1 & 1 & 1 & $1.61 \mathrm{E}-14$ \\
\hline 2 & M10 & $-18,694.8$ & 25 & $37,439.58$ & 1 & 0 & 1 & 0 & 1 & 1 & 1 & 1 & $9.33 \mathrm{E}-10$ \\
\hline 2 & M11 & $-18,676.2$ & 25 & $37,402.34$ & 1 & 1 & 0 & 0 & 1 & 1 & 1 & 1 & 0.639040 \\
\hline 2 & M12 & $-18,727.5$ & 25 & $37,504.90$ & 1 & 1 & 1 & 0 & 0 & 1 & 1 & 1 & $3.75 \mathrm{E}-24$ \\
\hline 2 & M13 & $-18,678.9$ & 25 & $37,407.70$ & 1 & 1 & 1 & 0 & 1 & 0 & 1 & 1 & 0.018167 \\
\hline 2 & M14 & $-18,677.1$ & 25 & $37,404.22$ & 1 & 1 & 1 & 0 & 1 & 1 & 0 & 1 & 0.147299 \\
\hline 2 & M15 & $-18,683.6$ & 25 & $37,417.10$ & 1 & 1 & 1 & 0 & 1 & 1 & 1 & 0 & 0.000109 \\
\hline 3 & M16 & $-18,707.9$ & 24 & $37,463.88$ & 0 & 1 & 0 & 0 & 1 & 1 & 1 & 1 & $1.57 \mathrm{E}-15$ \\
\hline 3 & M17 & $-18,697.1$ & 24 & $37,442.12$ & 1 & 0 & 0 & 0 & 1 & 1 & 1 & 1 & $1.02 \mathrm{E}-10$ \\
\hline 3 & M18 & $-18,727.6$ & 24 & $37,503.18$ & 1 & 1 & 0 & 0 & 0 & 1 & 1 & 1 & 3.63E-24 \\
\hline 3 & M19 & $-18,679.0$ & 24 & $37,405.94$ & 1 & 1 & 0 & 0 & 1 & 0 & 1 & 1 & 0.017960 \\
\hline 3 & M20 & $-18,677.2$ & 24 & $37,402.48$ & 1 & 1 & 0 & 0 & 1 & 1 & 0 & 1 & 0.143502 \\
\hline 3 & M21 & $-18,683.7$ & 24 & $37,415.36$ & 1 & 1 & 0 & 0 & 1 & 1 & 1 & 0 & 0.000106 \\
\hline 4 & M22 & $-18,709.0$ & 23 & $37,464.04$ & 0 & 1 & 0 & 0 & 1 & 1 & 0 & 1 & $1.56 \mathrm{E}-15$ \\
\hline 4 & M23 & $-18,698.4$ & 23 & $37,442.72$ & 1 & 0 & 0 & 0 & 1 & 1 & 0 & 1 & $8.07 \mathrm{E}-11$ \\
\hline 4 & M24 & $-18,731.5$ & 23 & $37,508.96$ & 1 & 1 & 0 & 0 & 0 & 1 & 0 & 1 & $2.11 \mathrm{E}-25$ \\
\hline 4 & M25 & $-18,681.1$ & 23 & $37,408.16$ & 1 & 1 & 0 & 0 & 1 & 0 & 0 & 1 & 0.005584 \\
\hline 4 & M26 & $-18,684.2$ & 23 & $37,414.48$ & 1 & 1 & 0 & 0 & 1 & 1 & 0 & 0 & 0.000183 \\
\hline
\end{tabular}

$\log L \log$-likelihood, $d f$ degrees of freedom, AIC Akaike information criterion, $F S$ fruit set, $F I$ flower intensity, $P D S$ percent damage score, $H$ height, $B A$ basal area, $g$ (gamma) female selection gradient, $b$ (beta) male selection gradient, 1/0, included/excluded, $N A$ not applicable

Acknowledgements We thank Lars Nørgaard Hansen and Carsten Tom Nørgaard for their help with fieldwork, Morten Alban Knudsen for his help with mapping, and Alexandra Dolynska for her help in the lab. We thank Danish Nature Agency for permission to perform the study and for the access to the historical records on the genetic origin of the planted ash trees in the forest. We also thank Oliver Gailing for his comments on an earlier version of the manuscript.

Funding Open Access funding enabled and organized by Projekt DEAL. This study was funded by the European Commission under the Forest and Nature for Society (FONASO) Erasmus Mundus Joint Doctorate Program and Villum Foundation (Grant No. VKR023062). Igor Jerzy Chybicki was supported by the statutory funds of Kazimierz Wielki University.

Data Availability The dataset generated and analysed during the current study is available in the University of Copenhagen Electronic Research Data Archive (ERDA). https://doi.org/10.17894/ucph.c39ad0ed-5ef243bf-8d06-f94870962f1c

\section{Compliance with ethical standards}

Conflict of interest The authors declare that they have no conflict of interest.

Open Access This article is licensed under a Creative Commons Attribution 4.0 International License, which permits use, sharing, adaptation, distribution and reproduction in any medium or format, as long as you give appropriate credit to the original author(s) and the source, provide a link to the Creative Commons licence, and indicate if changes were made. The images or other third party material in this article are included in the article's Creative Commons licence, unless indicated otherwise in a credit line to the material. If material is not included in the article's Creative Commons licence and your intended use is not permitted by statutory regulation or exceeds the permitted use, you will need to obtain permission directly from the copyright holder. To view a copy of this licence, visit http://creativecommons.org/licenses/by/4.0/. 


\section{References}

Adams WT, Birkes DS (1991) Estimating mating patterns in forest tree populations. In: Fineschi S, Malvolti ME, Cannata F, Hattemer HH (eds) Biochemical Markers in the Population Genetics of Forest Trees. SPB Academic Publishing, The Hague, the Netherlands, pp 157-172

Arnold TW (2010) Uninformative parameters and model selection using Akaike's information criterion. J Wildl Manag 74:11751178. https://doi.org/10.1111/j.1937-2817.2010.tb01236.x

Bacles CF, Burczyk J, Lowe AJ, Ennos RA (2005) Historical and contemporary mating patterns in remnant populations of the forest tree Fraxinus excelsior L. Evolution 59:979-990. https://doi. org/10.1111/j.0014-3820.2005.tb01037.x

Bacles CF, Lowe AJ, Ennos RA (2006) Effective seed dispersal across a fragmented landscape. Science 311:628. https://doi.org/10.1126/ science. 1121543

Bacles CFE, Ennos RA (2008) Paternity analysis of pollen-mediated gene flow for Fraxinus excelsior L. in a chronically fragmented landscape. Heredity 101(4):368. https://doi.org/10.1038/ hdy. 2008.66

Bai X, Rivera-Vega L, Mamidala P, Bonello P, Herms DA, Mittapalli O (2011) Transcriptomic signatures of ash (Fraxinus spp.) phloem. PloS One 6(1): e16368. https://doi.org/10.1371/journal.pone.0016368

Baral HO, Queloz V, Hosoya T (2014) Hymenoscyphus fraxineus, the correct scientific name for the fungus causing ash dieback in Europe. IMA Fungus 5(1):79-80. https://doi.org/10.5598/imafungus.2014.05.01.09

Bengtsson V, Stenström A (2017) Ash Dieback - a continuing threat to veteran ash trees? In: R. Vasaitis and R. Enderle (Eds.), Dieback of European Ash (Fraxinus spp.): Consequences and Guidelines for Sustainable Management. Sweden: Swedish University of Agricultural Sciences, pp 262-272

Bochenek GM, Eriksen B (2011) First come, first served: delayed fertilization does not enhance pollen competition in a windpollinated tree, Fraxinus excelsior L. (Oleaceae). Int J Plant Sci 172: 60-69. https://doi.org/10.1086/657298

Børja I, Timmermann V, Hietala AM, Tollefsrud MM, Nagy NE, VivianSmith A, Cross H, Sønstebø JH, Myking T, Solheim H (2017) Ash dieback in Norway - current situation. In: R. Vasaitis and R. Enderle (Eds.), Dieback of European Ash (Fraxinus spp.): Consequences and Guidelines for Sustainable Management. Sweden: Swedish University of Agricultural Sciences, pp 166-175

Bullock JM, Mallada González L, Tamme R, Götzenberger L, White SM, Pärtel M, Hooftman DA (2017) A synthesis of empirical plant dispersal kernels. J Ecol 105:6-19. https://doi. org/10.1111/1365-2745.12666

Burczyk J, Adams WT, Birkes DS, Chybicki IJ (2006) Using genetic markers to directly estimate gene flow and reproductive success parameters in plants on the basis of naturally regenerated seedlings. Genetics 173:363-372. https://doi.org/10.1534/genetics. 105.046805

Burczyk J, DiFazio SP, Adams WT (2004) Gene flow in forest trees: how far do genes really travel? For Genet 11:179

Burnham KP, Anderson DR (2002) Model selection and multimodel inference: a practical information-theoretic approach, 2nd edn. SpringerVerlag, Berlin

Cain ML, Milligan BG, Strand AE (2000) Long-distance seed dispersal in plant populations. Am J Bot 87:1217-1227. https://doi. org/10.2307/2656714

Chybicki IJ, Burczyk J (2009) Simultaneous estimation of null alleles and inbreeding coefficients. J of Heredity 100(1):106-13. https://doi. org/10.1093/jhered/esn088

Chybicki IJ, Burczyk J (2013) Seeing the forest through the trees: comprehensive inference on individual mating patterns in a mixed stand of Quercus robur and Q. petraea. AoB 112:561-574. https:// doi.org/10.1093/aob/mct131
Chybicki IJ (2018) NM $\pi$-improved re-implementation of NM+, a software for estimating gene dispersal and mating patterns. Mol Ecol Resour 18(1):159-168. https://doi.org/10.1111/1755-0998.12710

Coker TL, Rozsypálek J, Edwards A, Harwood TP, Butfoy L, Buggs RJ (2019) Estimating mortality rates of European ash (Fraxinus excelsior) under the ash dieback (Hymenoscyphus fraxineus) epidemic. Plants, People, Planet 1:48-58. https://doi.org/10.1002/ppp3.11

Denancé N, Sánchez-Vallet A, Goffner D, Molina A (2013) Disease resistance or growth: the role of plant hormones in balancing immune responses and fitness costs. Front PlantSci 4:155. https://doi. org/10.3389/fpls.2013.00155

Ellstrand NC, Elam DR (1993) Population genetic consequences of small population size: implications for plant conservation. Annu Rev Ecol Syst 24:217-242. https://doi.org/10.1146/annurev.es.24.110193.001245

Enderle R, Nakou A, Thomas K, Metzler B (2015) Susceptibility of autochthonous German Fraxinus excelsior clones to Hymenoscyphus pseudoalbidus is genetically determined. Ann For Sci 72:183-193. https://doi.org/10.1007/s13595-014-0413-1

Enderle R, Fussi B, Lenz HD, Langer G, Nagel R, Metzler B (2017) Ash dieback in Germany: research on disease development, resistance and management options. In: R. Vasaitis and R. Enderle (Eds.), Dieback of European Ash (Fraxinus spp.): Consequences and Guidelines for Sustainable Management (pp. 89-105). Sweden: Swedish University of Agricultural Sciences.

Enderle R, Stenlid J, Vasaitis R (2019) An overview of ash (Fraxinus spp.) and the ash dieback disease in Europe. CAB Rev 14:1-12. https:// doi.org/10.1079/PAVSNNR201914025

Eriksson G, Namkoong G, Roberds JH (1993) Dynamic gene conservation for uncertain futures. For Ecol Manage 62:15-37. https://doi. org/10.1016/0378-1127(93)90039-P

Evans MR (2019) Will natural resistance result in populations of ash trees remaining in British woodlands after a century of ash dieback disease? R Soc Open Sci 6:190908. https://doi.org/10.1098/rsos.190908

Gleiser G, Chybicki IJ, González-Martínez SC, Aizen MA (2018) Phenological match drives pollen-mediated gene flow in a temporally dimorphic tree. Plant Biol 20:93-100. https://doi.org/10.1111/ plb. 12651

Goto S, Shimatani K, Yoshimaru H, Takahashi Y (2006) Fattailed gene flow in the dioecious canopy tree species Fraxinus mandshurica var. japonica revealed by microsatellites. Molecular Ecology 15:2985-2996. https://doi.org/https://doi.org/10.1111/ j.1365-294X.2006.02976.X

Gross A, Holdenrieder O, Pautasso M, Queloz V, Sieber TN (2014) Hymenoscyphus pseudoalbidus, the causal agent of European ash dieback. Mol Plant Pathol 15:5-21. https://doi.org/10.1111/ mpp. 12073

Heydel F, Cunze S, Bernhardt-Römermann M, Tackenberg O (2015) Seasonal synchronization of seed release phenology promotes long-distance seed dispersal by wind for tree species with medium wind dispersal potential. J Veg Sci 26:1090-1101. https://doi. org/10.1111/jvs.12305

Hintze C, Heydel F, Hoppe C, Cunze S, König A, Tackenberg O (2013) D3: the dispersal and diaspore database-baseline data and statistics on seed dispersal. Perspect Plan Ecol Evol Sys 15(3):180-192. https://doi.org/10.1016/j.ppees.2013.02.001

Jackson ST, Lyford ME (1999) Pollen dispersal models in quaternary plant ecology: assumptions, parameters, and prescriptions. Bot Rev 65(1):39-75. https://doi.org/10.1007/BF02856557

Kalinowski ST (2005) hp-rare 1.0: a computer program for performing rarefaction on measures of allelic richness. Mol Ecol Notes 5(1):187-9.

Kjær ED, Wellendorf H (1997) Variation in flowering and reproductive success in a Danish Picea abies (Karst.) seed orchard. For Genet 4:181-188

Kjær ED, McKinney LV, Nielsen LR, Hansen LN, Hansen JK (2012) Adaptive potential of ash (Fraxinus excelsior) populations 
against the novel emerging pathogen Hymenoscyphus pseudoalbidus. Evol Appl 5(3):219-228. https://doi.org/10.1111/j. 1752-4571.2011.00222.x

Klein EK, Lavigne C, Gouyon PH (2006) Mixing of propagules from discrete sources at long distance: comparing a dispersal tail to an exponential. BMC Ecol 6(1):3. https://doi. org/10.1186/1472-6785-6-3

Kowalski T (2006) Chalara fraxinea sp. nov. associated with dieback of ash (Fraxinus excelsior) in Poland. For Pathol 36(4): 264-270. https://doi.org/10.1111/j.1439-0329.2006.00453.x

Kramer AT, Ison JL, Ashley MV, Howe HF (2008) The paradox of forest fragmentation genetics. Conserv Biol 22(4):878-885. https://doi.org/10.1111/j.1523-1739.2008.00944.x

Lefort F, Brachet S, Frascaria-Lacoste N, Edwards KJ, Douglas GC (1999) Identification and characterization of microsatellite loci in ash (Fraxinus excelsior L.) and their conservation in the olive family (Oleaceae). Molecular Ecology 8(6): 1088-1089. https:// doi.org/10.1046/j.1365-294X.1999.00655_8.x

Lenz HD, Bartha B, Straßer L, Lemme H (2016) Development of ash dieback in south-eastern Germany and the increasing occurrence of secondary pathogens. Forests 7(2):41. https://doi. org/10.3390/f7020041

Lobo A, Hansen JK, McKinney LV, Nielsen LR, Kjær ED (2014) Genetic variation in dieback resistance: growth and survival of Fraxinus excelsior under the influence of Hymenoscyphus pseudoalbidus. Scand J For Res 29(6):519-526. https://doi. org/10.1080/02827581.2014.950603

Lobo A, McKinney LV, Hansen JK, Kjær ED, Nielsen LR (2015) Genetic variation in dieback resistance in Fraxinus excelsior confirmed by progeny inoculation assay. Forest Pathol 45(5):379-387. https://doi.org/10.1111/efp.12179

Lõhmus A, Runnel K (2014) Ash dieback can rapidly eradicate isolated epiphyte populations in production forests: a case study. Biol Cons 169:185-188. https://doi.org/10.1016/j.biocon.2013.11.031

Marçais B, Husson C, Cael O, Dowkiw A, Saintonge FX, Delahaye L, Collet C, Chandelier A (2017) Estimation of ash mortality induced by Hymenoscyphus fraxineus in France and Belgium. Balt For 23(1):159-167

McKinney LV, Nielsen LR, Hansen JK, Kjær ED (2011) Presence of natural genetic resistance in Fraxinus excelsior (Oleraceae) to Chalara fraxinea (Ascomycota): an emerging infectious disease. Heredity 106(5):788-797. https://doi.org/10.1038/hdy.2010.119

McKinney LV, Nielsen LR, Collinge DB, Thomsen IM, Hansen JK, Kjær ED (2014) The ash dieback crisis: genetic variation in resistance can prove a long-term solution. Plant Pathol 63(3):485-499. https://doi.org/10.1111/ppa.12196

Molecular Ecology Resources Primer Development Consortium, Aggarwal RK, Allainguillaume J, Bajay MM, Barthwal S, Bertolino P, Chauhan P, Consuegra S, Croxford A, Dalton DL, den Belder E, Díaz-Ferguson E, Douglas MR, Drees M, Elderson J, Esselink GD, Fernández-Manjarrés JF, Frascaria-Lacoste N, Gäbler-Schwarz S, Garcia de Leaniz C, Ginwal HS, Goodisman MA, Guo B, Hamilton MB, Hayes PK, Hong Y, Kajita T, Kalinowski ST, Keller L, Koop BF, Kotzé A, Lalremruata A, Leese F, Li C, Liew WY, Martinelli S, Matthews EA, Medlin LK, Messmer AM, Meyer EI, Monteiro M, Moyer GR, Nelson RJ, Nguyen TT, Omoto C, Ono J, Pavinato VA, Pearcy M, Pinheiro JB, Power LD, Rawat A, Reusch TB, Sanderson D, Sannier J, Sathe S, Sheridan CK, Smulders MJ, Sukganah A, Takayama K, Tamura M, Tateishi Y, Vanhaecke D, Vu NV, Wickneswari R, Williams AS, Wimp GM, Witte V, Zucchi MI (2011) Permanent genetic resources added to Molecular Ecology Resources Database 1 August 2010-30 September 2010. Mol Ecol Resour 11(1):219-222. https://doi.org/10.1111/j.1755-0998.2010.02944.x

Morgan MT, Conner JK (2001) Using genetic markers to directly estimate male selection gradients. Evolution 55(2):272-281
Muñoz F, Marçais B, Dufour J, Dowkiw A (2016) Rising out of the ashes: additive genetic variation for crown and collar resistance to Hymenoscyphus fraxineus in Fraxinus excelsior. Phytopathology 106(12):1535-1543. https://doi.org/10.1094/PHYTO-11-15-0284-R

Nathan R, Klein E, Robledo-Arnuncio JJ, Revilla E (2012) Dispersal kernels: review. In: J. Clobert, M. Baguette, T. G. Benton \& J. M. Bullock (Eds.), Dispersal Ecology and Evolution (Chapter 15). United Kingdom: Oxford University Press.

Nielsen LR, McKinney LV, Olrik DC, Jensen V, Kjær ED (2009) Identity verification of trees in the 61 years old common ash (Fraxinus excelsior) clonal seed orchard FP202 (Birkemarken, Humlebæk) by DNA genotyping with microsatellite markers. Forest \& Landscape Working Papers (No. 34/2009). Denmark: Forest \& Landscape, University of Copenhagen

Noakes AG, Best T, Staton ME, Koch J, Romero-Severson J (2014) Cross amplification of 15 EST-SSR markers in the genus Fraxinus. Conserv Genet Resour 6(4):969-970. https://doi.org/10.1007/ s12686-014-0260-2

Obeso JR (2002) The costs of reproduction in plants. New Phytol 155(3):321-348. https://doi.org/10.1046/j.1469-8137.2002.00477.x

Pautasso M, Aas G, Queloz V, Holdenrieder O (2013) European ash (Fraxinus excelsior) dieback - a conservation biology challenge. Biol Cons 158:37-49. https://doi.org/10.1016/j.biocon.2012.08.026

Peakall RO, Smouse PE (2006) GENALEX 6: genetic analysis in Excel. Population genetic software for teaching and research. Mol Ecol Notes 6:288-95

Pliūra A, Lygis V, Suchockas V, Bartkevičius E (2011) Performance of twenty four European Fraxinus excelsior populations in three Lithuanian progeny trials with a special emphasis on resistance to Chalara fraxinea. Balt For 17:17-34

Queloz V, Hopf S, Schoebel CN, Rigling D, Gross A (2017) Ash dieback in Switzerland: history and scientific achievements. In: R. Vasaitis and R. Enderle (Eds.), Dieback of European Ash (Fraxinus spp.): Consequences and Guidelines for Sustainable Management. Sweden: Swedish University of Agricultural Sciences, pp 68-78

Robledo-Arnuncio JJ, Garcia C (2007) Estimation of the seed dispersal kernel from exact identification of source plants. Mol Ecol 16:50985109. https://doi.org/10.1111/j.1365-294X.2007.03427.x

Semizer-Cuming D, Kjær ED, Finkeldey R (2017) Gene flow of common ash (Fraxinus excelsior $\mathrm{L}$.) in a fragmented landscape. PLoS One 12(10): e0186757. https://doi.org/10.1371/journal.pone.0186757

Semizer-Cuming D, Finkeldey R, Nielsen LR, Kjær ED (2019) Negative correlation between ash dieback susceptibility and reproductive success: good news for European ash forests. Ann For Sci 76(1):16. https://doi.org/10.1007/s13595-019-0799-x

Semizer-Cuming D, Chybicki IJ, Finkeldey R, Kjær ED (2020) Raw data for "Gene flow and reproductive success in ash (Fraxinus excelsior L.) in the face of ash dieback: restoration and conservation". V1. University of Copenhagen Electronic Research Data Archive (ERDA). https://doi.org/10.17894/ucph. c39ad0ed-5ef2-43bf-8d06-f94870962f1c

Skovsgaard JP, Thomsen IM, Skovgaard IM, Martinussen T (2010) Associations among symptoms of dieback in even-aged stands of ash (Fraxinus excelsior L.). For Pathol 40(1): 7-18. https://doi. org/10.1111/j.1439-0329.2009.00599.x

Skovsgaard JP, Wilhelm GJ, Thomsen IM, Metzler B, Kirisits T, Havrdová L, Enderle R, Dobrowolska D, Cleary M, Clark J (2017) Silvicultural strategies for Fraxinus excelsior in response to dieback caused by Hymenoscyphus fraxineus. Forestry: An International Journal of Forest Research 90(4):455-472. https:// doi.org/10.1093/forestry/cpx012

Stener LG (2013) Clonal differences in susceptibility to the dieback of Fraxinus excelsior in southern Sweden. Scand J For Res 28(3):205-216. https://doi.org/10.1080/02827581.2012.735699

Thomasset M, Hodkinson TR, Restoux G, Frascaria-Lacoste N, Douglas GC, Fernández-Manjarrés JF (2014) Thank you for not 
flowering: conservation genetics and gene flow analysis of native and non-native populations of Fraxinus (Oleaceae) in Ireland. Heredity 112(6):596-606. https://doi.org/10.1038/hdy.2013.141

Thomsen IM, Skovsgaard JP (2012) Silvicultural strategies for forest stands with ash dieback. Forstschutz Aktuell 55:18-20

Trakhtenbrot A, Katul GG, Nathan R (2014) Mechanistic modeling of seed dispersal by wind over hilly terrain. Ecol Model 274:29-40. https://doi.org/10.1016/j.ecolmodel.2013.11.029
Wada KC, Takeno K (2010) Stress-induced flowering. Plant Signaling and Behavior 5(8):944-947. https://doi.org/10.4161/psb.5.8.11826

Wohlmuth A, Essl F, Heinze B (2018) Genetic analysis of inherited reduced susceptibility of Fraxinus excelsior L. seedlings in Austria to ash dieback. Forestry 91(4): 514-525. https://doi. org/10.1093/forestry/cpy012 